\title{
O LUGAR DA DEFICIÊNCIA INTELECTUAL NA PRODUÇÃO CIENTÍFICA SOBRE O ENSINO DE HISTÓRIA
}

\author{
The place of intellectual deficiency in scientific \\ production on the teaching of history
}

\author{
Anna Augusta Sampaio de Oliveira * \\ Katia de Moura Graça Paixão* \\ Glacielma de Fátima da Silva** \\ Ângelo Ântonio Puzipe Papim ${ }^{* * *}$
}

\begin{abstract}
RESUMO
O artigo busca levantar e analisar a produção científica sobre o ensino de História para os Estudantes com Deficiência Intelectual (EDI), no Ensino Fundamental II, focando as dissertações e teses produzidas sobre essa temática, no Brasil. Delimitamos o período de 2005 a 2016 para a pesquisa, feita na base de dados da CAPES. Como resultado, encontramos apenas dois (2) trabalhos que consideraram as possibilidades de ensino e aprendizado de história para os EDI. A escassez de pesquisas na área aponta o reflexo de uma política educacional, que, apesar do movimento
\end{abstract}

\footnotetext{
* Prof ${ }^{\mathrm{a}}$ Livre-docente do Departamento de Educação Especial da Faculdade de Filosofia e Ciências "Júlio de Mesquita Filho" no qual é docente nos cursos de Pedagogia e Fisioterapia e no Programa de Pós-graduação em Educação e coordenadora do Grupo de Estudos e Pesquisas em Inclusão Social (GEPIS). E-mail: anna64.oliveira@gmail.com

** Doutora em Educação pela Universidade Estadual Paulista "Júlio de Mesquita Filho", Marília-SP, Pedagoga da área de Educação Especial - UFSC e membro do Grupo de Estudos e Pesquisas em Inclusão Social (GEPIS). E-mail: kmgpaixao@gmail.com

*** Mestre em Educação da Unesp-Marília, Licenciada em História, Diretora de Escola e membro do Grupo de Estudos e Pesquisas em Inclusão Social (GEPIS). E-mail: sglacihistoria@gmail.com

**** Mestrando do Programa de Pós-graduação em Educação da UNESP- Marília, Psicólogo Clínico e Pedagogo e membro do Grupo de Estudos e Pesquisas em Inclusão Social (GEPIS). E-mail: angelopapim@gmail.com
} 
de inclusão, não favorece o ensino e aprendizado do EDI, todavia, apenas garante a matrícula escolar.

Palavras-chave: Ensino de História; Estudantes com Deficiência Intelectual; Produção científica.

\begin{abstract}
The article seeks to analyze and analyze the scientific production on the teaching of History for Students with Intellectual Disabilities (SID), in Elementary Education II, focusing on dissertations and theses produced on this subject in Brazil. We delimit the period from 2005 to 2016 for the research, made in the CAPES database. As a result, we found only two (2) papers that considered the possibilities of teaching and learning history for SID. The lack of research in the area points to the reflection of an educational policy that, despite the inclusion movement, does not favor SID teaching and learning, however, it only guarantees school enrollment.
\end{abstract}

Keywords: History teaching; Students with Intellectual Disabilities; Scientific production.

\title{
Introdução
}

Com o fim do período em que o Brasil foi governado pela Ditadura Militar (1964-1985) ${ }^{1}$ e a restauração do regime democrático, iniciou-se um processo de reestruturação do sistema educacional brasileiro. É nesse cenário de mudanças sociopolíticas que o ensino de História, antes substituído pela disciplina de Estudos Sociais, nas séries de $5^{\mathrm{a}}$ a $8^{\mathrm{a}}$ (atual Ensino Fundamental II, $6^{\circ}$ ao $9^{\circ}$ ano) ${ }^{2}$, voltou a

1 A ditadura militar foi implantada no Brasil em $1^{\circ}$ de abril de 1964 , com substancial apoio de pessoas e entidades da sociedade civil, de órgãos representativos do poder econômico nacional, de uma parte considerável dos superiores da hierarquia católica e ainda de importantes órgãos de comunicação de massa, os quais se proclamam tradicionalmente liberais. O sistema ditatorial, que durou de 1964 a 1985, teve diversas etapas e apresentou algumas características peculiares, como o fato de que o poder ditatorial não se apoiava num líder carismático, mas foi imposto e exercido sempre por grupos dominantes. (DALLARI, 2013).

2 O Parecer 853/71 (BRASIL, 1972), imposto pelo Conselho Federal de Educação, fixou o núcleo comum obrigatório para os currículos do $1^{\circ}$ e $2^{\circ}$ graus. A doutrina do Currículo da Lei n. 5692/71 (BRASIL, 1972) define os Estudos Sociais como integrante do currículo. Dessa forma, os conteúdos poderiam ser tratados como atividades $\left(1^{\mathrm{a}}\right.$ a $4^{\mathrm{a}}$ série do Primeiro Grau, sob o 
configurar no currículo oficial. Em consonância com as novas demandas daquele momento histórico, vários pesquisadores e professores passaram a discutir o lócus e a função do ensino de História na educação.

Zamboni (2000), ao analisar os trabalhos apresentados no III Encontro de Pesquisadores do Ensino de História, realizado em Campinas, em 1997, conclui, observando as diferentes linhas de pesquisa e os variados temas debatidos no encontro, que o ensino de História passava por um período de ressignificação, marcado por uma variedade de temas, choques de interesses e prioridades sociopolíticas.

É justamente nesse período que germina a discussão sobre os direitos das pessoas com deficiência. A Lei de Diretrizes e Bases da Educação (LDB) incorpora, em seu capítulo V, a perspectiva mundial de inclusão escolar e a matrícula preferencial na rede regular de ensino também para as pessoas com deficiência, as quais, naquele momento, como registra o documento, eram caracterizadas como "com necessidades especiais"3 (BRASIL, 1996). A LDB aqueceu a discussão sobre a inclusão, no cenário escolar nacional, contudo, ainda não se observa esse debate nas linhas de pesquisa de ensino de História com o foco no público-alvo da educação especial (PAEE) e, mais especificamente, no estudante com deficiência intelectual $(\mathrm{EDI})^{4}$, o que se pode observar nos estudos de Zamboni (2000) e, posteriormente, de Silva (2009; 2016).

nome de Integração Social); Áreas de Estudo ( $5^{\mathrm{a}}$ a $8^{\mathrm{a}}$ série do Primeiro Grau, sob o nome de Estudos Sociais) e Disciplina - História (somente no $2^{\circ} \mathrm{Grau}$ ). Como se pode observar, o ensino de História ficou restrito ao $2^{\circ} \mathrm{Grau}$, inserido na grade curricular com carga horária máxima de duas horas semanais, durante um ano desse curso. A obrigatoriedade do ensino de Estudos Sociais percorreu todo o período da Ditadura Militar Brasileira (1964-1985), período no qual, principalmente os professores e profissionais da História, foram objeto de perseguições e censuras. A imposição dos Estudos Sociais foi acompanhada de um grande movimento de resistência e luta pela volta do ensino de História, nas escolas brasileiras, configurando um novo momento na construção do código disciplinar da Didática da História. (SCHMIDT, 2006).

3 Após 2008, com a publicação da Política Nacional da Educação Especial na Perspectiva inclusiva, a terminologia necessidades educacionais especiais recebe a redação: Público-Alvo da Educação Especial (PAEE), o que se refere às pessoas com deficiências, altas habilidades/superdotação e transtornos globais de desenvolvimento. (BRASIL, 2015b, p. 12).

4 A deficiência intelectual nos documentos orientadores do MEC é caracterizada "[...] por alterações significativas, tanto no desenvolvimento intelectual como na conduta adaptativa, na forma expressa em habilidades práticas, sociais e conceituais.” (BRASIL, 2015b, p. 46). 
, neste estudo, a escolarização do EDI, sobretudo do ensino de História, tendo em vista que mais da metade dos alunos da Educação Especial matriculados em classes comuns da Educação Básica é constituído por pessoas com deficiência intelectual, conforme apontam os dados do Censo Escolar (BRASIL, 2015a), sendo, portanto, uma problemática muito recorrente no âmbito escolar que demanda estudos nessa área.

Tendo em vista que, amparado pela Convenção sobre os Direitos das Pessoas com Deficiência - ONU/2006 (BRASIL, 2011), da qual o Brasil é signatário, pelo Decreto $n^{\circ}$ 5296/2004 (BRASIL, 2004), o Censo Escolar/INEP “[...] considera estudantes com deficiência aqueles que têm impedimentos de longo prazo, de natureza física, intelectual ou sensorial, os quais, em interação com diversas barreiras, podem obstruir sua participação plena e efetiva na sociedade em igualdade de condições com as demais pessoas." (BRASIL, 2015b, p. 46).

A inclusão escolar de estudantes com deficiência intelectual, inclusive nas aulas de História, deve estar para além das limitações no funcionamento individual, entendendo que a deficiência "[...] não é fixada nem dicotomizada. Ela é fluida, contínua e mutável e, além disso, é possível reduzir a deficiência através de intervenções, serviços e apoios." (OLIVEIRA, 2011, p. 12).

Oliveira (2009, p. 73-74) aponta que "a condição de deficiência intelectual não pode nunca predeterminar qual será o limite de desenvolvimento do indivíduo. [...] Cabe à escola criar as condições necessárias [...] para a superação de seu próprio limite."

DDessa forma, é atribuído à escola um papel insubstituível, uma vez que, por meio do ensino, serão impulsionados novos processos de funcionamento mental no estudante (VYGOTSKI, 2000; OLIVEIRA, 2015) e, portanto, pesquisas sobre a escolarização do EDI são fundamentais.

A discussão das pesquisas, no âmbito da História, parece se concentrar nas questões de etnia e de gênero, igualmente importantes, mas insuficientes para que se possa pensar na amplitude do processo inclusivo, porque ao PAEE estão garantidas a matrícula e a permanência nas classes comuns do ensino regular.

A intensificação do movimento educacional inclusivo, no sentido da constituição de uma política nacional brasileira, teve maior 
impacto com a Declaração de Salamanca (BRASIL, 1997), da qual o Brasil se tornou signatário e que impulsionou a discussão do acesso de crianças, jovens e adultos, naquele momento denominados "com necessidades educacionais especiais", à educação.

Entretanto, nesse período, o Brasil iniciava a elaboração de diretrizes e ações inclusivas na direção apontada pelos documentos internacionais e pela própria LDB. Esse movimento se intensificou, com a publicação da Resolução CNE/CBE $n^{\circ}$ 02/2001, a qual instituiu diretrizes nacionais para a educação especial na educação básica (BRASIL, 2001a), e do Parecer CNEICBE no 17/2001(BRASIL, 2001b). É importante destacar que, nos Parâmetros Curriculares Nacionais (PCN) de História para os $3^{\circ}$ e $4^{\circ}$ ciclos do Ensino Fundamental (de $5^{\text {a }}$ a $8^{\text {a }}$ séries, $6^{\circ}$ ao $9^{\circ}$ ano), estipulados nesse período, reconheceu-se "[...] a realidade brasileira como diversa, e as problemáticas educacionais das escolas, das localidades e das regiões como múltiplas [...]" (BRASIL, 1998, p. 15), e, de certa forma, a proposta dos PCN permitiu à escola estabelecer novas abordagens pedagógicas para o ensino de História. Essas abordagens poderiam ser mais favorecedoras com respeito ao aprendizado de todos os estudantes e, por consequência, também ao aprendizado dos EDI, embora fosse um período no qual eles ou ainda estavam ausentes do ciclo II do Ensino Fundamental ou, graças ao seu número reduzido, não provocavam impacto nesse âmbito do ensino.

Conhecer o estudante, entender o contexto no qual ele está inserido e avaliar suas necessidades individuais, a fim de fixar as metodologias de ensino mais adequadas, são pontos fundamentais para garantir o sucesso de sua inclusão na escola regular. Porém, esses pontos nem sempre foram considerados, no cenário educacional brasileiro.

O processo histórico que assegurou as medidas que deveriam ser tomadas como forma de efetivar a inclusão deu-se com a aprovação da Resolução do Conselho Nacional de Educação/Conselho Pleno (CNE/CP) 1, de 18 de fevereiro de 2002, que definiu a meta de formar professores capazes de promover a aprendizagem do público-alvo da educação especial, inclusive os EDI (BRASIL, 2002).

Com essa Resolução, estipularam-se mudanças nas Diretrizes Curriculares Nacionais para a Formação de Professores da Educação 
Básica, nos cursos de licenciatura; assim, conforme previsto no seu art. $2^{\circ}$, o futuro docente deveria ser preparado para "o acolhimento e o trato da diversidade" (BRASIL, 2002, p. 1) e possuir "conhecimentos sobre crianças, adolescentes, jovens e adultos, aí incluídas as especificidades dos alunos com necessidades educacionais especiais $[\ldots] . "$

No entanto, as dificuldades para concretizar as deliberações da Resolução, que determinou aos cursos de formação de professores que se adaptassem às novas exigências no prazo de dois anos, deflagraram um cenário pouco receptivo a novos processos inclusivos. E, próximo do final do prazo para a adequação, a Resolução CNE/CP n ${ }^{\circ}$ 2, de 27 de agosto de 2004 (BRASIL, 2004b), prorrogou o prazo para 15 de outubro de 2005. Contudo, em 2005, uma nova Resolução foi publicada, na tentativa de viabilizar a implantação da Resolução CNE/CP 1/2002. Foi acrescentado à Resolução CNE/CP $\mathrm{n}^{\circ} 1$, de 17 de novembro de 2005, um novo parágrafo no art. 15 da Resolução de 2002: " $\$ 3^{\circ}$ As instituições de ensino superior decidirão pela aplicação, ou não, das Diretrizes Curriculares Nacionais para a Formação de Professores da Educação Básica, em nível superior [...]" (BRASIL, 2005, p. 17).

Apesar de todos os percalços, a Resolução foi implantada em 2005. Assim, escolhemos o ano de 2005 como data para o início de nosso levantamento, por estipular um marco legal que propulsionaria o levantamento de pesquisas com foco em adequações metodológicas na inclusão do PAEE. Dessa maneira, o presente estudo teve por objetivo mapear a produção científica sobre os métodos de ensino de História para os EDI, no Ensino Fundamental, ciclo II, entre o período de 2005 até 2016, focando as Dissertações e Teses produzidas.

\section{Procedimentos Metodológicos}

O levantamento foi realizado no site do Banco de Teses e Dissertações da CAPES. A busca contou com os seguintes 
descritores: Ensino de História AND Deficiência Intelectual; Métodos de Ensino; Ensino Fundamental II -obtendo-se um total de 866 resultados.

Para refinar os resultados, optamos pela escolha dos seguintes Programas de Pós-Graduação: Diversidade e Inclusão; Educação; Educação (Psicologia da Educação); Educação (Currículo); Educação - Processos formativos e desigualdades sociais; Educação e Contemporaneidade; Educação Escolar; Educação Especial (Educação do Indivíduo Especial; Educação, Contextos Contemporâneos e Demandas Populares; Educação: História, Política, Sociedade; Ensino; História; Processos Socioeducativos e Práticas Escolares; Psicologia do Desenvolvimento e Aprendizagem; Psicologia Escolar e do Desenvolvimento Humano.

Com essa filtragem, obtivemos 332 resultados. Essa opção por realizar o refinamento por nome do programa deveu-se à constatação de que, na ferramenta de filtragem Área de Concentração, havia um grande número de resultados (625 resultados) que não traziam a informação a qual tema de pesquisa pertenciam, ou seja, esse resultado não trazia maiores informações sobre o campo Área de Concentração.

Com o objetivo de restringir ainda mais os resultados, passamos à aplicação da ferramenta de refinamento Área de Concentração, quando selecionamos as alternativas que mais se aproximavam do nosso tema em estudo: Desenvolvimento e aprendizagem; Diversidade e Inclusão; Educação; Educação Brasileira; Educação do Indivíduo Especial; Educação e Formação; Educação Escolar; Educação Escolar e Profissão Docente; Educação Social; Educação, Contextos Contemporâneos e Demandas Populares; Educação, Sociedade e Práxis Pedagógica; Ensino na Educação Brasileira; Formação de Educadores; Planejamento Educacional; Processos Socioeducativas e Práticas Escolares.

Observamos que, com esse refinamento, resultaram, com o filtro Área de Concentração, 234 Teses e Dissertações, apresentadas entre parênteses e sem nenhuma informação adicional. Por não sabermos quais trabalhos foram agrupados no resultado 234, optamos por mantê-lo para análise mais aprofundada. Desse modo, chegamos ao resultado final de 304 dissertações e teses. 
A partir desse resultado, passamos à seleção das Dissertações e Teses, através da leitura de seus títulos e resumos. Nessa seleção, retornamos às palavras-chave, a fim de buscar trabalhos que abordassem o ensino de História para o EDI e suas metodologias de ensino, no Ensino Fundamental, ciclo II, selecionando Dissertações e Teses produzidas entre os anos de 2005 a 2016. Foi necessário que essa seleção por período ocorresse a partir da leitura dos trabalhos pré-selecionados. Devemos ainda esclarecer que o trabalho com as palavras-chave norteou nossa seleção, pois nos concentramos em Dissertações e Teses que abordassem o ensino de História para EDI, no Ensino Fundamental II, e suas metodologias de ensino.

Devido à dificuldade de encontrar todos os descritores contidos nos trabalhos, priorizamos, por meio da leitura, a busca de trabalhos que considerassem, ao menos, o Ensino de História para o EDI. Os trabalhos selecionados para a análise foram dois (2): uma Dissertação de Mestrado, denominada A concepção de êxito no ensino de História para alunos com deficiência intelectual, ${ }^{5}$ e uma Tese de Doutorado, com o título Construção, Aplicação e Análise de Proposta de Formação Continuada de Professores para o Ensino de História a Alunos com Deficiência Intelectual ${ }^{6}$, ambas do mesmo pesquisador (SILVA, 2009, 2016).

\section{Resultados e Discussão}

Os resultados obtidos com o uso dos descritores anteriormente mencionados e selecionados para análise encontram-se contemplados no Quadro 1.

O Quadro 1 contém os dois resultados obtidos no levantamento das Dissertações e Teses no Banco de Dados da CAPES, eleitos para análise, por se aproximarem mais do objetivo da 
pesquisa. Os dados foram dispostos em quatro colunas, contendo: autor, título do trabalho, natureza do trabalho e ano de publicação, para melhor identificação.

Em sua Dissertação de Mestrado, Silva (2009) realizou entrevistas com 14 EDI matriculados em classes regulares do Ensino Fundamental II e de 11 professores de História desses estudantes. Para a seleção dos sujeitos da pesquisa, Silva utilizou os dados contidos no Mapa de Atendimento de uma Diretoria Regional de Ensino do interior de São Paulo. Seu objetivo consistiu em compreender "a concepção de êxito no ensino de História para alunos com deficiência intelectual" (p. 01). O autor procurou, em sua pesquisa, comparar se essa concepção dos estudantes era semelhante à construída pelos professores desses estudantes.

Destaca-se um trecho que fundamenta a discussão proposta por Silva:

[...] vimos durante análise das "Condições Iniciais", que a História antes da presença dos alunos com deficiência intelectual, é compreendida pelos professores entrevistados como espécie de produto que deve ser entregue aos alunos responsáveis por "guardá-la".

Vimos ainda que esta mesma História possui objetivo funcional e imediato, mais precisamente voltado para uma boa nota na prova mensal, nos exames vestibulares ou nos concursos públicos [...].

As dificuldades para o aprendizado desta História estão em sua plenitude voltadas aos alunos, compreendidos como únicos responsáveis pelo fracasso na aprendizagem, ou seja, na aquisição e posterior reprodução do conteúdo que lhe foi entregue verbalmente ou através da leitura do livro didático (SILVA, 2009, p. 122)

Silva (2009) inferiu que a presença do EDI na classe comum modificou as intenções de ensino dos professores, pois eles deixaram de esperar que os EDI reproduzissem por escrito, em sala ou nas avaliações, o conteúdo transmitido, começando a avaliar apenas o 
comportamento dos estudantes, esperando que estes se adaptassem e não atrapalhassem o andamento da aula. Contudo, Silva (2009) concluiu que os EDI compreenderam o desempenho que era esperado deles e procuraram adaptar-se, o que nem sempre foi possível. Sobre isso, observe-se o apontamento do autor:

Por fim, aponta a importância do silenciamento e da adequação do comportamento de acordo com o esperado pelo professor como procedimento comum, pois reconhecem que ambos estão notavelmente associados ao êxito. (SILVA, 2009, p. 123).

O trabalho de Silva (2009) nos fornece pistas a respeito da contradição existente entre como e o que o professor deseja ensinar e a realidade do como e o que o aluno aprende. Essa contradição, segundo o autor, estende-se aos objetivos do ensino de História:

O ensino de história discursivamente voltado à humanização, reorganiza-se neste espaço de modo que promova o cíclico processo de sujeição através da entrega da maior quantidade possível de informações que serão cobradas logo a frente. Não há tempo para o debate, o aprendizado e mesmo à percepção do outro (SILVA, 2009, p. 125)

Porém, ele compreendeu que a inclusão dos EDI na escola regular tem o potencial de reverter essa situação, pois os mecanismos de adaptação usados com o corpo discente, em geral, podem não ser eficientes com os EDI, o que pode favorecer a reflexão e a mudança nas concepções de êxito, objetivos, métodos e práticas do ensino de História, por parte do professor de História e de toda a comunidade escolar.

Entretanto, enfatiza-se que o objetivo do trabalho de Silva (2009) não consistiu em oferecer alternativas metodológicas ao 
ensino de História para o EDI, apesar de trazer um avanço para a área, ao considerar o ponto de vista do estudante, e não apenas o do professor.

Na sequência de seus estudos e reflexões sobre o ensino de História, Silva (2016) aprofundou-se sobre o tema, em sua Tese de Doutorado. Sua pesquisa, dessa vez, teve por objetivo "construir, aplicar e analisar um modelo de formação continuada direcionada a professores de História para o ensino de alunos com deficiência intelectual" (p. 20). Ele abordou, em sua Tese, a necessidade de formação continuada que possibilitasse aos professores repensar suas concepções (não só a de aprendizado, ou êxito, como ele coloca em sua Dissertação de Mestrado, mas também a própria concepção de ensino de História e Deficiência Intelectual). Para alcançar esse objetivo, ele desenvolveu e aplicou um modelo de formação destinada a professores de História, com as seguintes características:

Esse modelo de formação propõe a realização de encontros de reflexão entre os professores e o pesquisador, com suporte de roteiros norteadores previamente estabelecidos, tendo como ferramenta propulsora da reflexão, a análise dialógica de filmagens do trabalho cotidianamente desenvolvido pelo professor em sala de aula. (SILVA, 2016, p. 69)

A pesquisa de Silva (2016) contou com a participação de 4 (quatro) integrantes: 2 professoras (1 de escola pública e 1 de escola particular) e 2 EDI matriculados no Ensino Fundamental II (1 na escola pública e 1 na escola particular). Através da observação das filmagens, ele comprovou algumas hipóteses. A principal delas é que o ensino de História se dividia em três fases: "a contação, a associação básica e a associação plena [...]”.

Para Silva (2016), na fase da contação, o professor "conta/apresenta" a História, sem exigir a participação do estudante; na associação básica, o professor possibilita ao estudante relacionar o conhecimento a ser aprendido com outros saberes, em nível primário (inicial); e, por fim, na associação plena, estabelece-se, por meio do questionamento 
e do diálogo, uma relação aprofundada entre o conteúdo apresentado e o contexto histórico, estendendo-os às situações cotidianas dos estudantes. Nesse último nível, como descreve o autor, ocorreria o aprendizado significativo, sendo esse o objetivo que os professores de História deveriam perseguir. Silva (2016), ao analisar os dados, constatou que até mesmo os EDI apresentaram possibilidades de fazer associações plenas.

Por ser a escola, o local onde se configura o ensino formal, consideramos que a Escola de Vygotski ou Teoria Histórico-Cultural (THC) possibilita algumas contribuições para as dificuldades encontradas no ensino escolar, ao voltar-se, principalmente, à importância e papel do educador no processo de aprendizagem. Essa teoria atribui ao educador um papel de essencial importância, para que ocorra a aprendizagem.

Pino (2005), a partir do estudo das obras de Vygotsky, afirma que a constituição cultural do ser humano só é possível através do outro, ou seja, da inter-relação. É pelas relações sociais que a mediação cultural entre o adulto e a criança acontece. Nessa relação, ocorre a apropriação do conhecimento socialmente construído pela criança. Vygotsky assim descreve a mediação:

La aplicación de medios auxiliares y el paso a la actividad mediadora reconstruye de raíz toda la operación psíquica a semejanza de como la aplicación de las herramientas modifica la actividad natural de los órganos y amplia infinitamente el sistema de actividad de las funciones psíquicas. (VYGOTSKY, 1995, p. 94)

O conceito de mediação foi uma importante contribuição de Vygotsky ao pensamento pedagógico. $\mathrm{Na}$ mediação, o papel do professor é fundamental na escolha dos recursos pedagógicos para os EDI. $O$ processo de mediação oferece a possibilidade de desenvolvimento dos Processos Psicológicos Superiores (PPS), pois favorece o estabelecimento de recursos e estratégias pedagógicas que se colocam entre a cultura e o estudante. 
Libâneo (2004, p. 5-6) afirma que

[...] a escola continua sendo uma instância necessária de democratização intelectual e política; (e) [...] que uma política educacional inclusiva deve estar fundamentada na ideia de que o elemento nuclear da escola é a atividade de aprendizagem, lastreada no pensamento teórico, associada aos motivos dos alunos, sem o que as escolas não seriam verdadeiramente inclusivas. (2004, p. $5-6)$

Com base na Teoria Histórico-Cultural (THC), pode-se realizar uma reflexão sobre o ensino de História para os EDI, utilizando os conceitos de mediação e de compensação ou supercompensação da deficiência. Vygotsky (1997) apresenta, por meio de seus estudos com pessoas com deficiência, a possibilidade de que elas compensem déficits, mas não como um processo natural, porque isso só se torna possível com uma intervenção adequada, sendo a mediação uma delas. Para Vygotsky, o movimento que promove a compensação no EDI, parte do professor, que deve

[...] conocer la peculiaridad del camino por el qual debe conducir al niño. La clave de la peculiaridad la brinda la ley de transformación del menos del defecto en el más de la compensación. (VYGOTSKY, 1997, p.17)

O professor, ao conhecer as particularidades de seu aluno, avaliará a sua forma de apresentar o conteúdo, questionando-se: qual forma mais adequada para ensinar História ao EDI? Porém, ao se voltar para os PCN de ensino de História, para tentar responder a essa questão, o professor se depara com a seguinte problemática: a caracterização dos objetivos do ensino de História.

Ressaltam os PCN de História: 
A História tem o papel de difundir e consolidar identidades no tempo, sejam étnicas, culturais, religiosas, de classes e grupos, de Estado ou Nação. Nele, fundamentalmente, têm sido recriadas as relações professor, aluno, conhecimento histórico e realidade social, em benefício do fortalecimento do papel da História na formação social e intelectual de indivíduos para que, de modo consciente e reflexivo, desenvolvam a compreensão de si mesmos, dos outros, da sua inserção em uma sociedade histórica e da responsabilidade de todos atuarem na construção de sociedades mais igualitárias e democráticas. (BRASIL, 1998, p. 29).

O papel da História, na educação, não deixa claro ao professor se essas competências podem ser desenvolvidas por todos os indivíduos, principalmente pelo EDI. E, portanto, levanta-se a questão de se seria possível estender esses objetivos para os EDI.

Barroco, Leonardo e Silva (2012), em comentário à concepção expressa pela Teoria Histórico-Cultural acerca do desenvolvimento humano, afirmam que objetivar-se como ser humano significa alcançar o desenvolvimento pleno de todas as potencialidades humanas, tornar-se um ser genérico, ou seja, um arquétipo de humanidade. Para isso, os autores reconhecem a importância da História, sublinhando que o indivíduo deve não só se inserir na História, como também se apropriar dos seus resultados e fazer deles órgãos de sua individualidade.

Desse modo, como é possível fazer com que o estudante se insira na História e se aproprie de seus resultados? Fazendo com que ele se compreenda como parte integrante da História, sujeito dela e produtor de si mesmo; permitindo que ele aprenda os conteúdos da disciplina e, por meio desse aprendizado, seja capaz de dar seu próprio significado ao conhecimento da História, que foi historicamente acumulado; finalmente, mostrando que ele é produto do processo histórico e agente desse mesmo processo.

Somente com um conhecimento e entendimento da História e das relações humanas como histórico-culturais e socialmente construídas, o estudante com ou sem DI poderá tomar consciência do seu tempo histórico (contexto), suas contradições e possibilidades. E, 
para atingir esse nível de desenvolvimento, o EDI dependerá de uma aprendizagem com mediações que favoreçam a apropriação dos conteúdos historicamente construídos.

Oliveira (2002) salienta, a partir do estudo das obras de Vygotsky, a relação entre o desenvolvimento dos PPS e o contexto histórico cultural em que o indivíduo vive. Enfatiza a autora:

A chave do pensamento de Vygotsky, que impulsionou seus estudos e suas pesquisas, é, certamente, a formação histórica e social da mente. No seu entender, os processos psicológicos superiores têm origem sociocultural e, as relações sociais se configuram como parte essencial da constituição da natureza humana. (OLIVEIRA, 2002, p. 33)

No entanto, o ensino de História, como se observou pelo próprio levantamento bibliográfico, ainda não corresponde a esses objetivos, e sua estrutura de ensino apresenta-se como de uma educação tradicional, também chamada por Paulo Freire de educação bancária. Para Freire (1996), a educação bancária (educação tradicional) tem o seguinte fundamento metodológico:

A narração, de que o educador é o sujeito, conduz os educandos à memorização mecânica do conteúdo narrado. Mais ainda, a narração os transforma em "vasilhas", em recipientes a serem "enchidos" pelo educador. Quanto mais vá "enchendo" os recipientes com seus "depósitos", tanto melhor educador será. Quanto mais se deixem docilmente "encher", tanto melhores educandos serão. (p.57, aspas do autor.)

A essa educação, denunciada por Freire (1996), contrapomos o que denominamos métodos de ensino de História diversificados, ou alternativos, que seriam responsáveis por superar a educação bancária/tradicional baseada na narração, no depósito de saberes 
desconectados de significado, a qual não problematiza o conteúdo e nem promove a reflexão.

A ausência de práticas pedagógicas diversificadas pode ser explicada, como aponta Calissi, pelo aumento da reprodução e distribuição de livros didáticos, no Brasil, a partir da década de 1960, o que, por um lado, contribuiu para a instrumentalização do professor e acesso do estudante a um suporte de leitura e ao conhecimento histórico; “[...] criou, porém, ao mesmo tempo, a problemática da massificação da informação e desfavoreceu metodologias alternativas." (CALISSI, 2004). O livro didático, muitas vezes, se torna um manual didático para toda aula de História e único instrumento pedagógico de muitos professores.

Para além dessa educação bancária, Schmidt defende que a docência na área de História contribui para o empoderamento dos estudantes: "A aula de História é o momento em que, ciente do conhecimento que possui, o professor pode oferecer a seu aluno a apropriação do conhecimento histórico existente, através de uma atividade com a qual ele retome a atividade que edificou esse conhecimento." (2010, p. 57).

No caso do EDI, o professor de História deve considerar as particularidades do processo de aprendizagem desses sujeitos, tendo em vista os conteúdos e conceitos a serem apreendidos do currículo escolar, o que demanda do professor uma atuação pedagógica planejada e intencional.

Entretanto, é preciso buscar pontos de intersecção entre os elementos constituintes do sujeito, seu modo de pensar e as estratégias de ensino, as quais tornem o estudante sujeito do seu processo de aprendizagem, em coautoria com o professor, para além dos limites impostos por sua deficiência.

A escola deve ensinar os estudantes a pensar, ou seja, desenvolver ativamente neles os fundamentos do pensamento contemporâneo, de sorte a organizar um ensino tal que impulsione o desenvolvimento, configurando-se, dessa forma, em um ensino desenvolvente (DAVIDOV, 1988).

Os trabalhos analisados por esta pesquisa nos ofereceram algumas indicações de caminhos a seguir, pois discutiram problemas estruturais inerentes à educação brasileira, os quais frustram as tentativas de inclusão dos EDI e impossibilitam o aprendizado e o 
desenvolvimento, não somente desses estudantes, como de muitos outros.

Concordamos com esses trabalhos quanto à necessidade de mudança de concepção no que concerne ao papel da História, seu ensino e sobre o EDI, frente a esse ensino, mas consideramos que as pesquisas sobre métodos que apresentem maior potencialidade de apropriação do conhecimento para o EDI provocariam também mudanças de concepção sobre a educação e o papel da escola, porque essas pesquisas levariam a variadas discussões, como, por exemplo: como o EDI aprende melhor? Quais recursos o professor deve utilizar para ajudá-lo a aprender mais? Os trabalhos também nos indicaram lacunas na formação inicial dos professores e assinalaram, na formação continuada, uma oportunidade de sanar essas falhas. Referindo-se aos cursos de formação inicial de professores de história, Silva (2016, p. 40) assinala:

[...] não encontramos nos centros de formação pesquisados, nenhuma disciplina específica com vistas a um melhor atendimento pedagógico do aluno com deficiência intelectual, mas conteúdos inseridos nas disciplinas de didática, prática de ensino e estágio supervisionado $[\ldots]$.

A situação exposta pelo autor é alarmante, visto que nos revela que a Resolução CNE/CP 1 de 2002 não surtiu efeito e está, ainda, distante dos resultados desejados em sua implementação. Em geral, os futuros professores de História terminam seus cursos de formação inicial sem nenhuma experiência quanto ao modo de ensinar ao EDI, o que faz com que adotem os métodos de ensino dos quais possuem maior conhecimento, ou seja, os métodos de ensino tradicional.

\section{Conclusões}


O levantamento sobre o ensino de História para EDI revelou que, apesar da obrigatoriedade de sua matrícula no Ensino fundamental II ser uma realidade, ainda é preciso que a formação inicial e a formação continuada ofereçam ao professor novas concepções de ensino e perspectivas metodológicas para o ensino de História aos EDI. Esse movimento em busca de diferenciados processos de ensino deve ocorrer em todo o processo educacional, segundo aponta a THC e não somente nos casos de inclusão escolar de estudantes com deficiência intelectual. Tal processo, considerando esse público, precisa oferecer condições adequadas de aprendizagem, o que configura um caminho para promover a inclusão.

Os trabalhos analisados apontam que o ensino de História para os EDI ainda se encontra em estágio embrionário e longe de ser efetivado. Apesar de termos, na LDB (1996) e nas Resoluções apresentadas, parâmetros que orientam os professores, em sua atuação, ou que procuram assegurar uma melhor formação dos futuros docentes para possibilitar aos EDI participar de uma escola preparada para ensiná-lo, constatamos que essas orientações e resoluções quase não provocaram modificações nas práticas e concepções dos professores. A realidade revelada pelo levantamento da produção de Teses e Dissertações, num período de 11 anos, apresentou apenas dois trabalhos que discutem essa temática, representando uma preocupação irrisória sobre o ensino de História para os EDI.

Como discutimos logo na introdução deste trabalho, a partir do estudo de Zamboni (2000), inferimos que a escassez de trabalhos que abordam o ensino de História para o EDI pode significar que ainda não superamos a inclusão efetiva de outros grupos historicamente excluídos, haja vista a luta por garantir a obrigatoriedade do ensino de História Afro-Brasileira e Indígena, no currículo oficial de História. Consideramos que essa luta é legítima e extremamente necessária, porém, reafirmamos o imperativo de entender que a inclusão do PAEE não é um processo idêntico à inclusão de outros grupos, social e economicamente excluídos.

A finalidade do ensino de História é garantir que todos os estudantes, com ou sem deficiência, se apropriem do conhecimento historicamente construído, como prescrevem as leis e os regimentos que constituem o ensino nacional. Os processos educacionais, por sua 
vez, precisam ser humanizados, ou seja, capazes de oferecer aos estudantes acesso ao conhecimento humano, a fim de que esse conteúdo seja apropriado e possibilite o desenvolvimento de seres humanos integrais, não fragmentados, dotados de consciência e entendimento de seus papéis como seres sociais e integrantes da História.

A História, ao facultar a aprendizagem dos conceitos científicos, conforme as mediações realizadas pelo professor, em situações concretas e problematizadoras, assume um papel fundamental no desenvolvimento das Funções Psíquicas Superiores (como memória, atenção, linguagem, pensamento).

ComoConforme aponta Libâneo (2004, p. 22), devemos entender que "[...] o papel da educação escolar no mundo contemporâneo implica saber que a aquisição de conhecimentos e o desenvolvimento de capacidades mentais dos alunos incluem o conhecimento teórico, juntamente com o desenvolvimento de competências cognitivas complexas."

A mediação é um recurso pedagógico fundamental para o processo de aprendizagem do EDI, mas, para que seja empregada, é necessário que o professor compreenda a forma adequada de operacionalizar esse recurso, em sala de aula, de modo a explorar todas as suas possibilidades pedagógicas. A escola e os métodos adotados, na perspectiva da THC, inclusive para o ensino de História, necessitam se voltar para o desenvolvimento do potencial humano de seus estudantes, inclusive dos EDI, suscitando o aparecimento de novas formas de pensamento. Dessa forma, poderemos oferecer um cenário educacional que desenvolva o homem ao máximo de suas possibilidades.

\section{Referências Bibliográficas}

BARROCO, Sônia Mari Shima; LEONARDO, Nilza Sanches Tessaro; SILVA, Tânia dos Santos Alvarez (Org.) Educação Especial 
e Teoria Histórico-Cultural: em defesa da humanização do homem. Maringá: EDUEM, 2012. p. 42-65.

BRASIL. Presidência da República, Secretaria Especial dos Direitos Humanos. Declaração de Salamanca e linha de ação sobre necessidades educativas especiais. Brasília, DF: Coordenadoria Nacional para Integração da Pessoa Portadora de Deficiência CORDE, 1997.

BRASIL. Parâmetros Curriculares Nacionais - terceiro e quarto ciclos do ensino fundamental - História e Geografia. Brasília: MEC/SEF, 1998.

BRASIL. Ministério da Educação. Diretrizes Nacionais para a Educação Especial na Educação Básica. Brasília: Conselho Nacional de Educação (CNE), 2001a.

BRASIL. Ministério da Educação. Parecer CNElCBE no 17. Diário Oficial da União, 17/8/2001. Seção 1, Brasília, 2001b. p. 46.

BRASIL. Resolução CNE/CP 1/2002. Diário Oficial da União. Brasília, 9 de abril de 2002. Seção 1, p. 31. Disponível em: http://portal.mec.gov.br/cne/arquivos/pdf. Acesso em: 20 jan. 2016.

BRASIL. Decreto $\mathrm{n}^{\circ}$ 5.296/2004, de 2 de dezembro de 2004. Presidência da República: Brasília, 2004a. Disponível em: <http://www.planalto.gov.br/ccivil_03/_ato20042006/2004/decreto/d5296.htm>. Acesso em: 14 mar. 2016.

BRASIL. Resolução CNE 2/2004. Diário Oficial da União, Brasília, $1^{\circ}$ de setembro de 2004, Seção 1, p. 17, 2004b. Disponível em: http://portal.mec.gov.br/cne/arquivos/pdf. Acesso em: 15 de janeiro de 2016.

BRASIL. Resolução CNE/CP 1/2005. Diário Oficial da União, Brasília, 23 de novembro de 2005. Seção 1, p. 17, 2005. Disponível em: http://portal.mec.gov.br/cne/arquivos/pdf. Acesso em: 15 jan. 2016.

BRASIL. Convenção sobre os Direitos das Pessoas com Deficiência: Protocolo Facultativo à Convenção sobre os Direitos das Pessoas com Deficiência: Decreto Legislativo $\mathrm{n}^{\circ} 186$, de 09 de julho de 2008: 
Decreto $\mathrm{n}^{\mathrm{o}}$ 6.949, de 25 de agosto de 2009. 4. ed., rev. e atual. Brasília: Secretaria de Direitos Humanos, Secretaria Nacional de Promoção dos Direitos da Pessoa com Deficiência, 2011. Disponível em:

<http://www.pessoacomdeficiencia.gov.br/app/sites/default/files/publi cacoes/convencaopessoascomdeficiencia.pdf $>$. Acesso em: $02 \mathrm{dez}$. 2015.

BRASIL. Indicadores da Educação Especial. Brasília: MEC, 2015a. Disponível em: http://portal.mec.gov.br/index.php?option=com_docman\&view=dow nload\&alias $=17655$-secadi-principais-indicadores-da-educacaoespecial\&category_slug=junho-2015-pdf\&Itemid=30192\%20. Acesso em: 10 abr. 2016.

BRASIL. Orientações para implementação da Política de Educação Especial na perspectiva da Educação Inclusiva. Brasília, DF: MEC, 2015b. Disponível em: http://portal.mec.gov.br/index.php?option=com_docman\&view=dow nload\&alias $=17237$-secadi-documento-subsidiario2015\&Itemid=30192 . SCHMIDT, Maria Auxiliadora. Acesso em: 20 jan. 2016.

CALISSI, Luciana. Historiografia didática. In: FLORES, Elio Chaves; BEHAR, Regina (Org.). A formação do historiador: tradições e descobertas. João Pessoa: Editora Universitária, 2004. p.47-61.

DALLARI, Dalmo de Abreu. A ditadura brasileira de 1964. São Paulo: DHNET, 2013. Disponível em: http://www.dhnet.org.br/direitos/militantes/dalmodallari/dallari_ditad ura_brasileira_de_1964.pdf. Acesso em: 20 fev. 2016.

DAVIDOV, Vasili Vasilievich. La enseñanza y el desarrolo psíquico. Moscou: Editorial Progreso, 1988.

FREIRE, Paulo. Pedagogia do Oprimido. São Paulo: Paz e Terra, 1996.

LIBÂNEO, J. C. A didática e a aprendizagem do pensar e do aprender: a teoria histórico-cultural da atividade e a contribuição de Vasili Davydov. Revista Brasileira de Educação, Rio de Janeiro, n. 
27, p. 5-24, 2004. Disponível em: <http://www.scielo.br/pdf/rbedu/n27/n27a01.pdf>. Acesso em: 08 nov. 2016.

OLIVEIRA, Anna Augusta Sampaio de. Representações sociais sobre educação especial e deficiência: o ponto de vista de alunos deficientes e professores especializados. 2002. 350 f. Tese (Doutoramento) Universidade Estadual Paulista, Marília, 2002.

OLIVEIRA, Anna Augusta Sampaio de. Estratégias para o ensino inclusivo na área da deficiência intelectual: alguns apontamentos. In: MARQUEZINE, M. C.; MANZINI, E. J.; BUSTO, R. M.; TANAKA, E. D. O.; FUJISAWA, D. S. (Org.). Políticas públicas e formação de recursos humanos em educação especial. Londrina: ABPEE, 2009. p.69-82.

OLIVEIRA, Anna Augusta Sampaio de. Aprendizagem escolar e Deficiência Intelectual: a questão da avaliação curricular. In: PLESTCH, M. D.; DAMASCENO, A. (Org.). Educação Especial e inclusão escolar: reflexões sobre o fazer pedagógico desde a Educação Infantil até o Ensino Superior. Rio de Janeiro: Editora EDUR, 2011. p.10-22.

Estudos na área da deficiência intelectual: avaliação pedagógica, aprendizagem e currículo escolar. 2015. 358f. Tese. (Livre-Docência em Educação Especial) - Universidade Estadual Paulista "Júlio de Mesquita Filho". UNESP, campus de Marília. 2015.

PINO, Angel. As marcas do humano - as origens da constituição cultural da criança na perspectiva de Lev S. Vigotski. São Paulo: Cortez, 2005.

SCHMIDT, Maria Auxiliadora. Estado e construção do código disciplinar da Didática da História. Perspectiva, Florianópolis, v. 24, n. 2, p. 709-729, jul./dez. 2006. Disponível em: http://www.perspectiva.ufsc.br. Acesso em: 20 maio 2016.

A formação do professor de História e o cotidiano da sala de aula. In: BITTENCOURT, Circe Maria FernandesBRASIL. (Org.). O saber histórico na sala de aula.11. ed. São Paulo: Contexto, 2010. p. 54-66. 
SILVA, Luís Henrique. A concepção de êxito no ensino de História para alunos com deficiência intelectual. 2009. 128p. Dissertação (Mestrado) -UNESP -FFC- Marília, 2009. Disponível em: http://bancodeteses.capes.gov.br/banco-teses/\#/. Acesso em: 26 maio 2016.

SILVA, Luís Henrique. Construção, Aplicação e Análise de Proposta de Formação Continuada de Professores para o Ensino de História a Alunos com Deficiência Intelectual. 2016. 180p. Tese (Doutorado) UNESP -FFC- Marília, 2016. Disponível em: http://bancodeteses.capes.gov.br/banco-teses/\#/. Acesso em: 26 maio 2016.

VYGOTSKY. Obras Escogidas - tomo III. Madrid: Visor, 1995.

VYGOTSKY, Lev Semenovich. Fundamentos da Defectologia. Obras Escogidas V. Madrid: Visor, 1997.

ZAMBONI, Ernesta. Panorama das pesquisas no ensino de História. Saeculum, Revista de História. João Pessoa-PB, n. 6/7, jan./dez. 2000. Disponível em: https://moodle.ufsc.br/pluginfile.php/834355/mod_resource/content/1 /Zamboni\%20-\%20Saeculum.pdf. Acesso em: 15 jan. 2015.

RECEBIDO EM: 18/04/2017 APROVADO EM: 03/07/2018 